\title{
Term Structure Modelling by Using Nelson-Siegel Model ${ }^{\#}$
}

\author{
Hana HLADÍKOVÁ ${ }^{*}$ - Jarmila RADOVÁ ${ }^{* *}$
}

The term structure of interest rates is defined as the relationship between the yields of default-free pure discount (zero-coupon) bonds and their time to maturity. The term structure is not always directly observable because, with the exception of short-term treasury-bills, most of the substitutes for default-free bonds (government bonds) are not pure discount bonds. Therefore, an estimation methodology is required to derive the zero coupon yield curves from observable data. If we deal with approximations of empirical data to create yield curves it is necessary to choose suitable mathematical functions. The first class is parametric models. This class of function-based models includes the model proposed by Nelson and Siegel (1987) and its extension by Svensson (1994). Alternative approach uses linear combinations of basis functions, defined over the entire term-to-maturity spectrum, to fit the discount function. This is referred to as a function-based construction of the yield curve. Bolder and Gusba (2002), Marciniak (2006), Li (2002) provide an extensive review and comparison of a number of estimation algorithms.

As to the Czech coupon bond market, the construction of yield curve has not yet been satisfactorily explored. Construction of yield curves by the Svensson method is dealt with in Slavík (2001), Radová, Málek and Štěrba (2007) and Kladívko (2009).

\# This article has been prepared with the contribution of funds from the institutional support to long-term conceptual development of research, development and innovation at the Faculty of Finance and Accounting of the University of Economics, Prague in 2012.

* RNDr. Hana Hladíková, Ph.D. - Researcher; Department of Economics, Faculty of Economics, University of Economics Prague, W. Churchill sq. 4, 13067 Prague, Czech Republic; <hana.hladikova@vse.cz>.

** Doc. RNDr. Jarmila Radová, Ph.D. - Associate Professor; Department of Banking and Insurance, Faculty of Finance and Accounting, University of Economics Prague, W. Churchill sq. 4, 13067 Prague, Czech Republic; <jarmila.radova@vse.cz>. 
The model of Nelson and Siegel (1987) and its extension by Svensson (1994) are used by central banks and other market participants as a model for the term structure of interest rates BIS (2005).

In Section 2 we define Nelson-Siegel model and propose an iterative method to solve arising nonlinear least squares problem. The minimization problem is stated in terms of the observed and computed prices rather than in terms of the observed and computed yields to maturity (YTM's). In Section 4 the data sample from the Czech coupon bond market is described. In Section 5 numerical experiments on these data are performed. Two data sets are used to test the method: i) a data set for a single day and ii) a larger data set selected in the time period from the year 2002 to 2011 .

\section{Term structure}

There are three equivalent descriptions of the term structure of interest rates (Málek, 2005):

- the discount function which specifies zero-coupon bond (with a par value \$1) prices as a function of maturity,

- the spot yield curve which specifies zero-coupon bond yields (spot rates) as a function of maturity,

- the forward yield curve which specifies zero-coupon bond forward yields (forward rates) as a function of maturity.

We will use the following notation:

\begin{tabular}{|l|l|}
\hline$t$ & time to payment (measured in years) \\
\hline$T$ & time to maturity \\
\hline$d(t, T)$ & $\begin{array}{l}\text { the discount function, that is the present value } \\
\text { of a unit payment due in time } t\end{array}$ \\
\hline$z(t, T)$ & $\begin{array}{l}\text { spot rate of maturity } t, \text { expressed as the } \\
\text { continuously compounded annual rate }\end{array}$ \\
\hline$f(t, T)$ & $\begin{array}{l}\text { continuously compounded instantaneous } \\
\text { forward rate at time } t\end{array}$ \\
\hline$N$ & number of bonds \\
\hline$P_{i}^{A s k}, P_{i}^{\text {Bid }}$ & observed price (offer), price (ask) \\
\hline
\end{tabular}


Hladíková H. - Radová J.: Term Structure Modelling Using Nelson-Siegel Model.

\begin{tabular}{|l|l|}
\hline$P_{i}=\frac{P_{i}^{B i d}+P_{i}^{A s k}}{2}$ & price \\
\hline$\widetilde{P}_{i}$ & theoretical price of the $i$-th bond \\
\hline$t_{i j}$ & $\begin{array}{l}\text { the time when the } j \text {-th payment of the } i \text {-th } \\
\text { bond occurs }\end{array}$ \\
$t_{i}=\left[t_{i 1}, \ldots, t_{i l_{i}}\right]$ & $\begin{array}{l}\text { difference of time to maturity and the } j \text {-th } \\
\text { payment of the } i \text {-th bond }\end{array}$ \\
\hline$m_{i j}=T_{i}-t_{i j}$ & the j-th payment of the $i$-th bond \\
\hline$c_{i j}$ & \\
\hline$c_{i}=\left[c_{i 1}, \ldots c_{i l_{i}}\right]^{T}$ & duration of the $i$-th bond \\
\hline$d\left(t_{i}\right)=\left[d\left(t_{i 1}\right), \ldots d\left(t_{i l l}\right)\right]$ & discount function \\
\hline$D_{i}$ &
\end{tabular}

There are three equivalent descriptions of the term structure of interest rates: the discount function $\mathrm{d}$, the spot yield curve $\mathrm{z}$ and forward yield curve $f$. We use $m=T-t$ to denote the time to maturity.

$$
\begin{aligned}
d(m) & =e^{-(m) z(m)}, \quad z(m)=\frac{-\ln (d(m))}{m}, \\
f(m) & =\frac{\partial}{\partial m} \ln (-d(m))=z(m)+(m) z^{\prime}(m), \\
& \int_{0}^{m} f(u) d u \\
z(m) & =\frac{0}{m} .
\end{aligned}
$$

\section{The Nelson-Siegel model}

We observe the set of coupon bond prices that are traded in the bond market at a given point in time. We minimize the weighted sum of the squared deviations of the fitted prices from the quoted prices.

Nelson-Siegel (1985) suggested forward curve to be estimated as: 
$f(m)=\beta_{0}+\beta_{1} e^{-\frac{m}{\tau}}+\frac{m}{t} \beta_{2} e^{-\frac{m}{\tau}}$

The model has interesting economic interpretation of parameters and good asymptotical characteristics (Seppälä and Viertiö, 1996).

- $\lim _{m \rightarrow \infty} f(m)=\beta_{0}, \quad \lim _{m \rightarrow 0} f(m)=\beta_{0}+\beta_{1}$,

- The value of parameter $\beta_{0}>0$, represents the asymptote of zero coupon yield curve function,

- The asymptote of forward curve as remained maturity approaches to infinity and can be interpreted as long term interest rate,

- The sum of parameters $\beta_{0}+\beta_{1}$ represent initial value of forward curve $f(0)=\beta_{0}+\beta_{1}$, which can be interpreted as instantaneous spot interest rate, thus we require $\beta_{0}+\beta_{1}>0$.

- The value of parameter $\beta_{1}$ represents the deviation of the function values from the asymptote and can intuitively be explained as the curvature of the function or as the difference between long term and short term forward interest rates.

Using (1) we obtain from Equation (2) the zero coupon rate $z$ and the discount function $d$ as follows:

$$
\begin{aligned}
& z(m)=\frac{1}{m} \int_{0}^{m} \beta_{0}+\beta_{1} e^{-\frac{u}{\tau}}+\frac{u}{\tau} \beta_{2} e^{-\frac{u}{\tau}} d u= \\
& =\beta_{0}+\left(\beta_{1}+\beta_{2}\right)\left[\frac{1-e^{-\frac{m}{\tau}}}{\frac{m}{\tau}}\right]-\beta_{2} e^{-\frac{m}{\tau}}, \\
& d(m)=e^{-m . z(m)}=e^{-m\left(\beta_{0}+\left(\beta_{1}+\beta_{2}\right)\left[\frac{1-e^{-\frac{m}{\tau}}}{\frac{m}{\tau}}\right]-\beta_{2} e^{-\frac{m}{\tau}}\right)}
\end{aligned}
$$


Let $\theta=\left(\beta_{0}, \beta_{1}, \beta_{2}, \tau\right)^{\mathrm{T}}$. The theoretical price $P_{i}$ of bond number $i$ is given by the sum of the discounted values of its cash flows, which using (4) is:

$$
P_{i}(\theta)=\sum_{j=1}^{l_{i}} c_{i j} d\left(m_{i j}, \theta\right)=\sum_{j=1}^{l_{i}} c_{i j} e^{-m_{i j} z\left(m_{i j}, \theta\right)}
$$

The final step is to actually estimate the parameters of the NelsonSiegel model. A natural requirement is to find these parameters such that the theoretical prices $P_{i}$ are as close as possible to the observed prices $\bar{P}_{i}$. Thus, in the sense of the least squares method we want to find a set of parameters $\beta_{0}, \beta_{1}, \beta_{2}, \tau$ that minimizes the function $H(P)$ given as,

$H(P):=\sum_{i=0}^{N} w_{i}\left(P_{i}-\bar{P}_{i}\right)^{2}$, where $w_{i}$ is weight of the $i$-th bond.

Our choice for the weights $w_{i}$ will be described in Section 3 .

We need to estimate four parameters: $\beta_{0}, \beta_{1}, \beta_{2}, \tau$ and for $N$ observed prices with different maturities $T_{1}, \cdots T_{N}$, we have $N$ equations.

There is a natural strategy to obtain parameters for this model: fix parameter $\tau$, and then estimate the $\beta_{0}, \beta_{1}, \beta_{2}$ values with least squares method. The model's parameters can change over time. We define $\theta_{\tau}=\left(\beta_{0}, \beta_{1}, \beta_{2}\right)^{\mathrm{T}}$ and

$$
\begin{aligned}
\widetilde{P}_{i}\left(\theta_{\tau}\right) & =\sum_{j=1}^{m_{i}} c_{i j} d\left(m_{i j}, \theta_{\tau}\right)= \\
& \left.=\sum_{j=1}^{l_{i}} c_{i j} e^{-m_{i j}\left(\beta_{0}+\left(\beta_{1}+\beta_{2}\right)\right.}\left[\frac{1-e^{-\frac{m_{i j}}{\tau}}}{\frac{m_{i j}}{\tau}}\right]-\beta_{2} e^{-\frac{m_{i j}}{\tau}}\right) .
\end{aligned}
$$


We let $\widetilde{P}\left(\theta_{\tau}\right)=\left[\widetilde{P}_{1}\left(\theta_{\tau}\right), \cdots \widetilde{P}_{N}\left(\theta_{\tau}\right)\right]^{T}$ be a vector of theoretical prices for the set of $N$ bond observations. Our objective, therefore, is to solve the minimization problem.

$$
\min _{\theta_{\tau}}\left(\left(P-\widetilde{P}\left(\theta_{\tau}\right)\right)^{T} W\left(P-\widetilde{P}\left(\theta_{\tau}\right)\right)\right.
$$

where $W$ is an $N \times N$ weighting matrix.

Equation (8) is a nonlinear least-squares problem. We apply the following nonlinear optimization algorithm (see e.g. Fischer, Nychka a Zervos, 1994):

- Employ the linear first-order Taylor series approximation:

$$
\widetilde{P}\left(\theta_{\tau}\right) \approx \widetilde{P}\left(\theta_{\tau}^{0}\right)-\left(\theta_{\tau}-\theta_{\tau}^{0}\right) X\left(\theta_{\tau}^{0}\right), \text { where } X\left(\theta_{\tau}\right)=\frac{\partial \widetilde{P}\left(\theta_{\tau}\right)}{\partial \theta_{\tau}{ }^{T}}
$$

- Define:

$$
Y\left(\theta_{\tau}^{0}\right)=P-\widetilde{P}\left(\theta_{\tau}^{0}\right)+\theta^{0} X\left(\theta^{0}\right),
$$

- Solve the linear least-squares approximation to the original problem given as:

$$
\begin{aligned}
& \min _{\theta_{\tau}}\left(Y\left(\theta_{\tau}^{0}\right)-\theta_{\tau} X\left(\theta_{\tau}^{0}\right)\right)^{T} W\left(Y\left(\theta_{\tau}^{0}\right)-\theta_{\tau} X\left(\theta_{\tau}^{0}\right)\right), \text { which is } \\
& \text { solved by, } \theta_{\tau}^{1}=\left(X\left(\theta_{\tau}^{0}\right)^{T} W X\left(\theta_{\tau}^{0}\right)\right)^{-1}\left(X\left(\theta_{\tau}^{0}\right)^{T} W Y\left(\theta_{\tau}^{0}\right)\right)
\end{aligned}
$$

- Return to Step 1 with $\theta^{0}:=\theta^{1}$ until convergence is not achieved.

Note that the above algorithm defined by Equations (9) to (11) is well suited for finding a local minimum of problem (8). The question whether this local minimum is also a global minimum will be addressed in Section 4 (cf. Gauthier and Simonato, 2012). We also did not impose any constraints on $\beta$ 's $\left(\beta_{0}>0, \beta_{0}+\beta_{1}>0\right)$. It seems that if the problem is well posed then these constraints are automatically satisfied for 'reasonable' values of $\tau$.

Alternatively, in place of using observed and theoretical prices in Equation (6) we can minimize the error of observed and theoretical yields to maturity (YTM's) to find the Nelson-Siegel model parameters. 


\section{Data from the Czech coupon bond market}

The Czech market is small and not as liquid as other developed markets. The original life of the Czech government bond is from 3 to 50 years. The government issued bonds with annual coupon payments. We consider here data for a selected day as given in Tab. 1 .

Tab. 1: Government coupon bonds (22 ${ }^{\text {nd }}$ February 2010).

\begin{tabular}{|l|r|r|r|r|r|}
\cline { 2 - 6 } \multicolumn{1}{c|}{} & Coupon & Maturity & Duration & Price+AUV & $\begin{array}{c}\text { Years to } \\
\text { maturity }\end{array}$ \\
\hline CZ0001000731 & 6,4 & 14.4 .10 & - & 106,3589 & 0,139726 \\
\hline CZ0001001242 & 2,55 & 18.10 .10 & 0,64 & 101,8496 & 0,652055 \\
\hline CZ0001002158 & 4,1 & 11.4 .11 & 1,08 & 106,7261 & 1,131507 \\
\hline CZ0001000764 & 6,55 & 5.10 .11 & 1,53 & 110,7972 & 1,616438 \\
\hline CZ0001001887 & 3,55 & 18.10 .12 & 2,49 & 104,5524 & 2,654795 \\
\hline CZ0001000814 & 3,7 & 16.6 .13 & 3,03 & 105,9092 & 3,315068 \\
\hline CZ0001001143 & 3,8 & 11.4 .15 & 4,47 & 105,6644 & 5,134247 \\
\hline CZ0001000749 & 6,95 & 26.1 .16 & 4,95 & 119,4099 & 5,928767 \\
\hline CZ0001001903 & 4 & 11.4 .17 & 5,91 & 103,8389 & 7,136986 \\
\hline CZ0001000822 & 4,6 & 18.8 .18 & 6,8 & 105,7394 & 8,490411 \\
\hline CZ0001002471 & 5 & 11.4 .19 & 7 & 109,8111 & 9,136986 \\
\hline CZ0001001317 & 3,75 & 12.9 .20 & 8,31 & 94,89792 & 10,56164 \\
\hline CZ0001001945 & 4,7 & 12.9 .22 & 9,13 & 101,5281 & 12,56164 \\
\hline CZ0001001796 & 4,2 & 4.12 .36 & 14,95 & 87,945 & 26,8 \\
\hline CZ0001002059 & 4,85 & 26.11 .57 & 17,64 & 93,69903 & 47,79178 \\
\hline
\end{tabular}

Source: www.patria.cz, personal computing

We exclude two bonds with less than three months to maturity, since the yields on these securities often seem to behave oddly and one bond with more than forty-seven years to maturity, since the price of the bond will evidently include also another risk premium. 


\section{Numerical experiments}

With the set of data described in Section 3 we performed a couple of numerical experiments. We used a computer program of our own developed for these purposes.

\subsection{Criteria to evaluate different yield curve construction methods}

As to the weights associated with each bond, general idea is that higher weights should be placed on bonds that we believe to have observed prices that are more accurate estimates of their true prices. Many authors use the reciprocal of the modified duration $D_{i}$ (see Tab. 2, weights labelled by 1 and 11 ). We tried to find a measure that would reflect the liquidity of the bond. Considering the data available from the market we propose a reciprocal of the difference between $P_{i_{A}}$ and $P_{i_{B}}$ ( $P_{i_{A}}$ - price (offer), $P_{i_{B}}$ - price (ask)). It is believed that this measure reflects to some extent bond's liquidity (see Tab. 2, weights labelled by 12 and 13$)$.

Tab. 2: Weights $w_{i}$ associated with bonds (labeled by numbers)

\begin{tabular}{|c|c|}
\hline Weight & Description \\
\hline $\mathbf{0}$ & $w_{i}=1$, \\
\hline $\mathbf{1 0}$ & $w_{i}=\frac{1}{N}$ \\
\hline $\mathbf{1}$ & $w_{i}=\frac{\frac{1}{\sum_{j=1}^{N} \frac{1}{\left(P_{i A}-P_{i B}\right)^{2}}},}{\left.\mathbf{P}_{j B}\right)^{2}}$ \\
\hline $\mathbf{1 1}$ & $w_{i}=\frac{1}{D_{i}}$, \\
& $w_{i}=\frac{1}{\sum_{j=1}^{N} \frac{1}{D_{j}}}$, \\
\hline
\end{tabular}




$13 \quad w_{i}=\frac{\left(\frac{1}{D_{i}}+\frac{1}{\left(P_{i A}-P_{i B}\right)^{2}}\right)}{\sum_{j=1}^{N}\left(\frac{1}{D_{j}}+\frac{1}{\left(P_{j A}-P_{j B}\right)^{2}}\right)}$

The tested methods are evaluated according to various criteria. The most important criterion is the goodness of fit. It is a measure of the difference of observed and theoretical (=computed) values. We compare errors of observed prices and theoretical prices in accordance with the minimization problem (10). Moreover, in place of prices the yields to maturity (YTM) are also employed. The criteria are summarized in Tab. 3.

Tab. 3: Errors of observed prices and yields

\begin{tabular}{|l|l|}
\hline$L 2_{P}=\sum_{i=1}^{N}\left(\bar{P}_{i}-P_{i}\right)^{2}$, & $\operatorname{RMSE}_{P}=\sqrt{\sum_{i=1}^{N} \frac{\left(\bar{P}_{i}-P_{i}\right)^{2}}{N}}$ \\
$L 2_{Y T M}=\sum_{i=1}^{N}\left(\overline{Y T M}_{i}-Y T M_{i}\right)^{2}$ & $\operatorname{RMSE}_{Y T M}=\sqrt{\frac{\sum_{i=1}^{N} \frac{\left(\overline{Y T T} \bar{M}_{i}-Y T M_{i}\right)^{2}}{N}}{N}}$ \\
\hline$L 2 W_{P}=\sum_{i=1}^{N}\left(\bar{P}_{i}-P_{i}\right)^{2} w_{i}$, & $M A E_{P}=\sum_{i=1}^{N} \frac{\left|\bar{P}_{i}-P_{i}\right|}{N}$ \\
$L 2 W_{Y T M}=\sum_{i=1}^{N}\left(\bar{Y}_{T} \bar{M}_{i}-Y T M_{i}\right)^{2} w_{i}$ & $M A E_{Y T M}=\sum_{i=1}^{N} \frac{\left|\overline{Y T M_{i}}-Y T M_{i}\right|}{N}$ \\
\hline$H R_{P}=\frac{\operatorname{card}\left(\bar{P}_{i}, P_{i}^{O} \leq \bar{P}_{i} \leq P_{i}^{B}\right)}{N}$ & $H R_{Y T M}=\frac{\operatorname{card}\left(\overline{Y T M}_{i}, Y T M_{i}^{O} \leq \overline{Y T M}_{i} \leq Y T M_{i}^{B}\right)}{N}$ \\
\hline
\end{tabular}

Another criterion is a smoothness of the obtained solution. Two measures of maximum smoothness of a curve $y=g(x)$ between $a$ and $b$ are used in Tab. 4. 
Tab. 4: . Two measures of maximum smoothness

\begin{tabular}{|l|l}
\hline$s(g)=\int_{a}^{b} \sqrt{1+\left[g^{\prime}(x)\right]^{2}} d x$ & $h(g)=\int_{a}^{b} g^{\prime \prime}(x)^{2} d x$
\end{tabular}

The last criterion is the stability of the solution. We measure here how the results change if one bond is excluded from the set of bonds. The less sensitivity of the solution to this change in data the better is the stability of the method.

\subsection{Initial test data sample}

Our initial tests revealed that values of $\tau$ could be restricted to $0<\tau<12$ (cf. Gilli at al., 2010). For a fixed $\tau$ we repeatedly solved minimization problem (8) to obtain $\beta_{0}, \beta_{1}, \beta_{2}$ applying algorithm defined by Equations (9) to (11). For these solutions we compared the $L 2 W P$ errors of observed and estimated prices (see Fig. 1). The least $L 2 W P$-error was obtained for value $\tau=6,7$. For this solution we computed the discount, forward and spot yield curves (Fig. 2). In order to check the quality of our solution we compared the results with a time consuming global optimization strategy. This global strategy used coarse-fine bracketing of the four parameters requiring over one million attempts. In terms of the $L 2 W$-error the global strategy did not find a better solution for our test data.

Fig. 1: The L2-error, L2W-error (in prices) and L2-error (in yields, YTM = Yield To Maturity) for different values of $\tau$

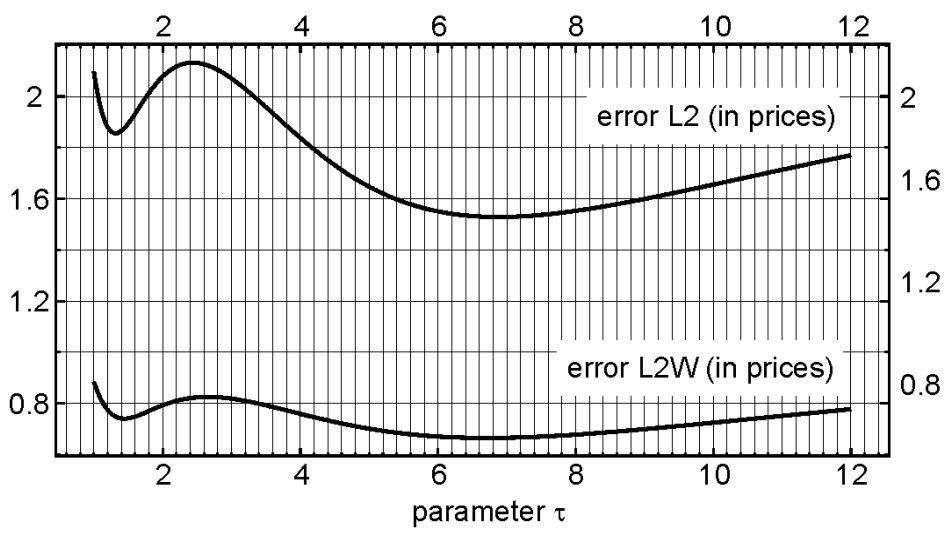


Hladíková H. - Radová J.: Term Structure Modelling Using Nelson-Siegel Model.

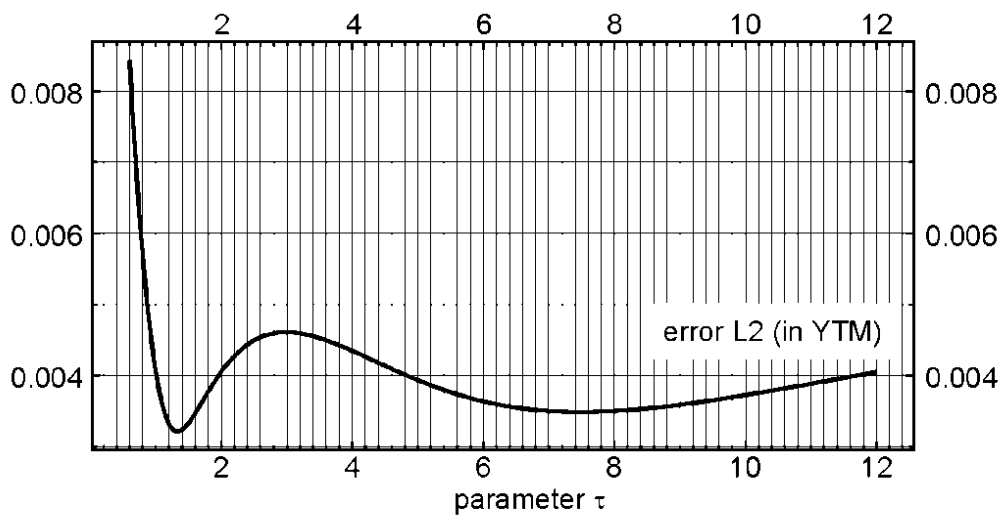

Fig. 2: Parameters $\beta_{0}, \beta_{1}, \beta_{2}$ and $\beta_{0}+\beta_{1}$ computed for different
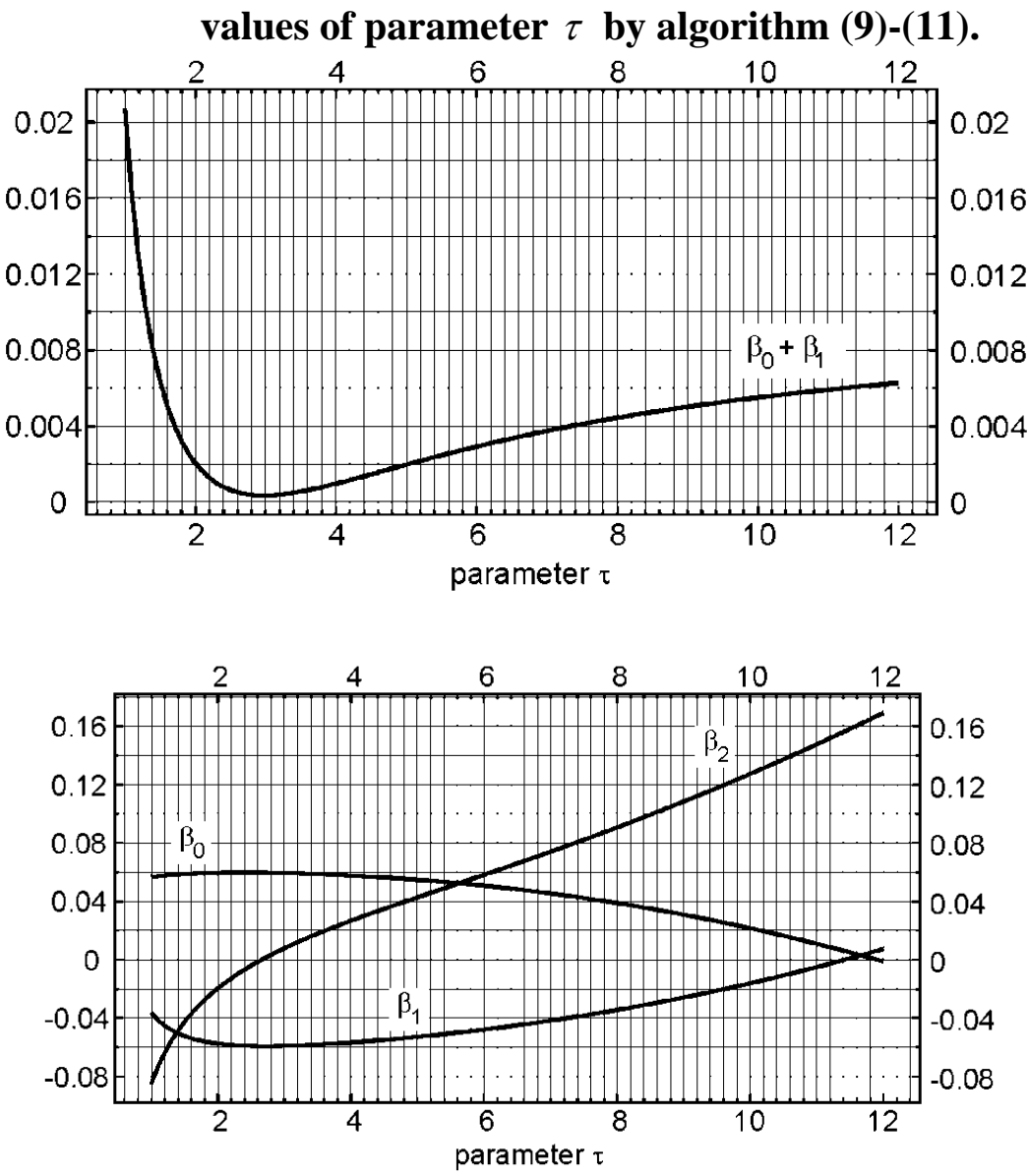


\section{Fig. 3: Comparison of spot and forward curves for solutions with} and without weights.

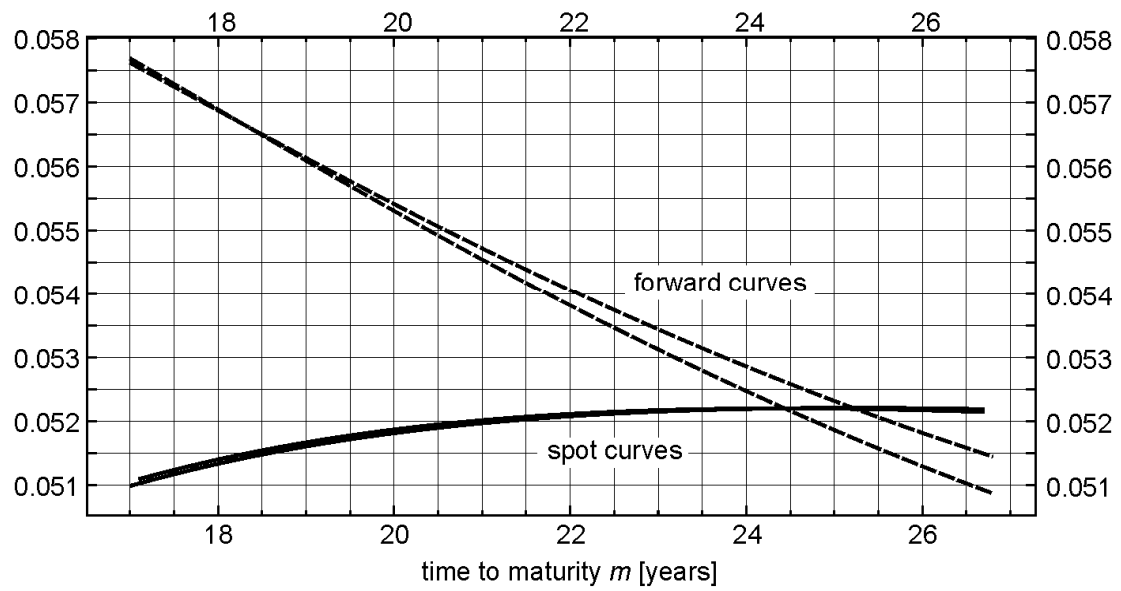

The error in prices does not show erratic behavior in dependence on parameter $\tau$ (Fig. 1). The minimization algorithm (9) - (11) found always the global minimum. Its convergence was fast and robust. The results were compared with a global strategy where we used values of $\beta_{0}, \beta_{1}, \beta_{2}, \tau$ from given intervals. The initial coarse estimates were: $0<\beta_{0}<0.15,-0.15<\beta_{1}<0.3,-0.3<\beta_{2}<0.3,0<\tau<30$. For given $\beta_{0}, \beta_{1}, \beta_{2}, \tau$ 's we recorded not only the $L 2 W_{p}$ (objective function in Equation (6)) but also the other measures of error, namely $R M S E 2_{P}$, $M A E_{P}, L 2_{P}$. Moreover, the $M A E_{Y T M}$ and $L 2_{Y T M}$ errors were used to measure the error of observed and computed YTM's. Computed solutions of the minimization problem (6) with and without weights are given in Tab. 5. It is apparent that the obtained coefficients $\beta_{0}, \beta_{1}, \beta_{2}, \tau$ do not differ much. The use of the reciprocal of the modified duration as a weight $w_{i}$ in Equation (6) does not show much influence on the obtained solution. This is also demonstrated in Figure 3 where we can see the differences in solutions with and without weights only on the long end. Similar behavior was observed when weights $1,10,12$ and 13 (see Tab. 2) were employed. 
Hladíková H. - Radová J.: Term Structure Modelling Using Nelson-Siegel Model.

\subsection{Numerical experiments on data of a single day $\left(22^{\text {nd }}\right.$ February 2010)}

In this section the problem of finding the most appropriate weight function $w_{i}$ is addressed. The considered weights are defined in Tab. 2 . We use the following notation: the Nelson-Siegel model using the weight labeled by number 10 in Tab. 2 is referred to as NS-10. The basic characteristics of the solutions obtained for arising variants of the NelsonSiegel model are given in Tab. 5.

Tab. 5: Characterization of the obtained solutions

\begin{tabular}{|l|c|c|c|c|c|c|c|l|r|}
\hline Methods & $\tau$ & $\beta_{0}$ & $\beta_{1}$ & $\beta_{2}$ & $\beta_{0}+\beta_{1}$ & $\begin{array}{c}\text { Est. } \\
\text { repo } \\
\mathbf{\%})\end{array}$ & Weight & $\begin{array}{l}\text { Measure } \\
\text { of error }\end{array}$ & $\begin{array}{c}\text { Error } \\
\text { value }\end{array}$ \\
\hline $\boldsymbol{N S}-\mathbf{0}$ & 6,8 & 0,0466 & $-0,0429$ & 0,0712 & 0,0037 & 0,3723 & 0 & $\mathrm{~L}_{2} \mathrm{~W}_{\mathrm{P}}$ & 1,551 \\
\hline $\boldsymbol{N S}-\mathbf{1}$ & 6,7 & 0,0471 & $-0,0435$ & 0,0700 & 0,0036 & 0,3553 & 10 & $\mathrm{~L}_{2} \mathrm{~W}_{\mathrm{P}}$ & 0,690 \\
\hline $\boldsymbol{N S - 1 0}$ & 6,8 & 0,0466 & $-0,0429$ & 0,0712 & 0,0037 & 0,3723 & 1 & $\mathrm{~L}_{2} \mathrm{~W}_{\mathrm{P}}$ & 0,430 \\
\hline $\boldsymbol{N S - 1 1}$ & 6,7 & 0,0471 & $-0,0435$ & 0,0700 & 0,0036 & 0,3553 & 11 & $\mathrm{~L}_{2} \mathrm{~W}_{\mathrm{P}}$ & 0,307 \\
\hline $\boldsymbol{N S}-12$ & 6,8 & 0,0468 & $-0,0427$ & 0,0703 & 0,0041 & 0,4082 & 12 & $\mathrm{~L}_{2} \mathrm{~W}_{\mathrm{P}}$ & 0,290 \\
\hline $\boldsymbol{N S}-13$ & 6,7 & 0,0472 & $-0,0434$ & 0,0694 & 0,0038 & 0,3783 & 13 & $\mathrm{~L}_{2} \mathrm{~W}_{\mathrm{P}}$ & 0,300 \\
\hline
\end{tabular}

The length and curvature of the methods is compared in Tab. 6 and the different measures of error are compared in Tab. 7. The obtained values do not differ much.

Tab. 6: Evaluation of the obtained solutions according to the length of the curves and smoothness

\begin{tabular}{|l|l|l|l|l|l|l|}
\hline \multicolumn{2}{|l|}{ Length } & \multicolumn{4}{l|}{ Smoothness } \\
\hline Method & Disc. & Spot & Forward & Disc, & Spot & Forward \\
\hline NS-12 & 26,71213 & 26,70011 & 26,70027 & 0,448111 & 0,005572 & 0,036056 \\
\hline NS-13 & 26,71213 & 26,70011 & 26,70027 & 0,456511 & 0,005769 & 0,037327 \\
\hline NS-0 & 26,71214 & 26,70011 & 26,70027 & 0,456987 & 0,005692 & 0,036836 \\
\hline NS-1 & 26,71214 & 26,70011 & 26,70027 & 0,462255 & 0,005848 & 0,037841 \\
\hline NS-10 & 26,71214 & 26,70011 & 26,70027 & 0,456987 & 0,005692 & 0,036836 \\
\hline NS-11 & 26,71214 & 26,70011 & 26,70027 & 0,462255 & 0,005848 & 0,037841 \\
\hline
\end{tabular}


Tab. 7: Evaluation of the obtained solutions according to accuracy of price and YTM estimations.

\begin{tabular}{|c|c|c|c|c|c|}
\hline \multicolumn{4}{|l|}{ Price } & \multicolumn{2}{|l|}{ YTM (\%) } \\
\hline Metoda & MAE $_{P}$ & $\mathrm{RMSE}_{\mathbf{p}}^{2}$ & $\mathbf{H R}_{\mathbf{P}}$ & MAE $_{\mathbf{Y T M}}$ & L2 $2_{\mathrm{YTM}}$ \\
\hline NS-10 & 0,335413 & 1,550521 & 46,153850 & 0,081133 & 0,382984 \\
\hline$N S-0$ & 0,335413 & 1,550521 & 46,153850 & 0,081133 & 0,382984 \\
\hline NS-12 & 0,326716 & 1,557360 & 46,153850 & 0,075320 & 0,381208 \\
\hline$N S-13$ & 0,331547 & 1,552912 & 46,153850 & 0,078989 & 0,382176 \\
\hline NS-11 & 0,337244 & 1,550938 & 46,153850 & 0,082533 & 0,385758 \\
\hline$N S-1$ & 0,337244 & 1,550938 & 46,153850 & 0,082533 & 0,385758 \\
\hline
\end{tabular}

Our attempt to find the most appropriate weight function is summarized in Tab. 8 where the ranking of each method with respect to the selected criterion is depicted. The column denoted as Suml is a sum of these rankings. The last column (Sum2) is a weighted sum of these rankings with higher weights imposed on the criteria of the goodness of fit in prices and YTM's rather than on the criteria of smoothness and curvature. In terms of Sum 2 the best performance shows methods NS-1 and $N S-11$. Both methods use the reciprocal of the modified duration $D_{i}$. We prefer $N S-11$ since the normalized value seems to be a more proper choice.

Tab. 8: Ranking of the methods according to separate criteria

\begin{tabular}{|l|c|c|c|c|c|c|c|c|}
\cline { 2 - 10 } \multicolumn{1}{c|}{} & \multicolumn{1}{l|}{ Price } & \multicolumn{4}{c|}{ YTM (\%) } \\
\hline Methods & MAE & L2 & RMSE & L2W & HR & MAE & L2 & RMSE \\
\hline NS-10 & 2 & 1 & 1 & 4 & 1 & 5 & 5 & 5 \\
\hline NS-0 & 1 & 1 & 1 & 6 & 1 & 5 & 5 & 5 \\
\hline NS-1 & 3 & 3 & 3 & 5 & 1 & 2 & 1 & 1 \\
\hline NS-11 & 5 & 3 & 3 & 3 & 1 & 2 & 1 & 1 \\
\hline NS-12 & 6 & 6 & 5 & 1 & 5 & 2 & 1 & 1 \\
\hline NS-13 & 3 & 5 & 6 & 2 & 5 & 1 & 1 & 4 \\
\hline
\end{tabular}


Hladíková H. - Radová J.: Term Structure Modelling Using Nelson-Siegel Model.

\begin{tabular}{|l|r|r|r|r|r|r|c|r|}
\hline \multicolumn{4}{|l|}{ Length } & \multicolumn{3}{l|}{ Smoothness } & \multicolumn{2}{l|}{} \\
\hline Methods & Disc. & Spot & Forw. & Disc. & Spot & Forw. & Sum1 & Sum2 \\
\hline NS-10 & 5 & 3 & 4 & 1 & 1 & 1 & 39 & 28,5 \\
\hline NS-0 & 1 & 3 & 1 & 1 & 1 & 1 & 33 & 27,5 \\
\hline NS-1 & 2 & 3 & 1 & 4 & 3 & 3 & 35 & 23,5 \\
\hline NS-11 & 5 & 3 & 4 & 4 & 3 & 3 & 41 & 25 \\
\hline NS-12 & 3 & 1 & 1 & 6 & 6 & 6 & 50 & 33 \\
\hline NS-13 & 3 & 1 & 1 & 3 & 5 & 5 & 45 & 29,5 \\
\hline
\end{tabular}

For the solution obtained by $N S-11$ we computed the discount, forward and spot yield curves (Fig. 4). On the upper side the discount function $d$ is depicted (horizontal axis represents time in years and the vertical axis the price of zero coupon bond with the nominal value of 1) and on the lower side the forward yield curve $f$ and the spot yield curve $z$ are depicted.

Fig. 4: Computed discount function, spot and forward rates vs. time for $N S-11$.
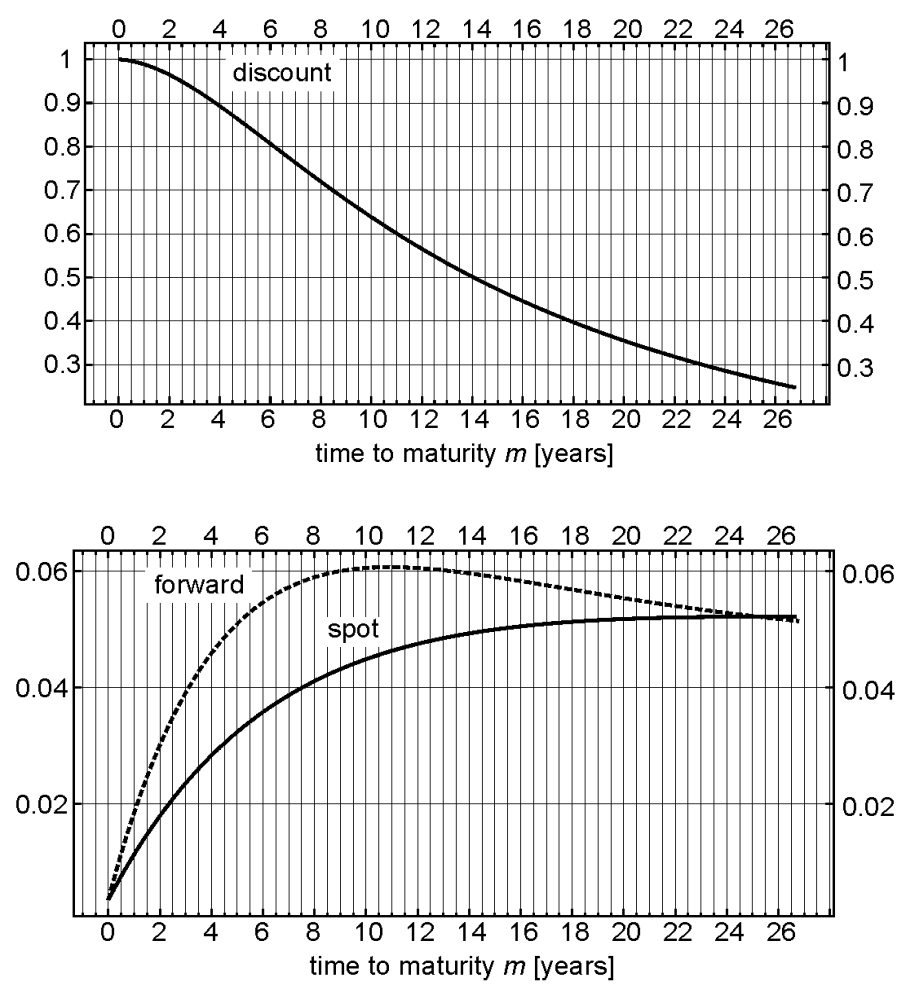
From our solutions we obtain estimates of the instantaneous forward rate curve from the Czech government coupon bonds. We can understand this estimate as an approximation of the market expectations regarding the future short-term interest rates. We can see that the starting value of estimated forward rate (column $\beta_{0}+\beta_{1}$ in Tab. 5) does not fit quite well the actual repo rate (the repo rate set by $\breve{C} \mathrm{NB}$ was $1 \%$ on $22^{\text {nd }}$ February 2010). The estimated value is between $0.35 \%$ and $0.48 \%$ - it is below the actual repo rate. The estimates do provide picture of evolution of the forward curve. This is a low level of the expected repo rate in the near future. The figures also show the gradually increasing forward curve. This corresponds to expectations of a gradual increase of the repo rate, which was consistent with market expectations as measured by CNB. Despite these expectations the repo rate dropped to value of $0,75 \%$ on $7^{\text {th }}$ May 2010.

\subsection{Numerical experiments on data of the complete time sequence 2002 - 2011}

The methods are compared on a data sample from the Czech coupon bond market obtained from the period of time between the years 2002 and 2011. The criteria employed for data of a single day (Section 4.3) are also used here. Moreover we add the criterion of the stability of the solution where the sensitivity of the method to the change in data is considered. The stability analysis employed evaluates how the results change if successively one bond is excluded from the set of bonds. The change in the resulting yield curves for the reduced and original sets of bonds is a measure of the stability of the method. The less sensitivity of the solution to this change in data the better is the stability of the method.

The analysis was performed on data for each single trading day from $2^{\text {nd }}$ January 2002 to $19^{\text {th }}$ January 2011, which amounts to 2273 trading days with altogether 32068 items (one item is a bond in a given trading day). Such a comprehensive analysis was carried out by means of our computer program developed for these purposes. 
Hladíková H. - Radová J.: Term Structure Modelling Using Nelson-Siegel Model.

Tab. 9: Ranking of the methods according to separate criteria (on the complete time sequence between the years 2002 and 2011)

\begin{tabular}{|c|c|c|c|c|c|c|c|c|c|c|c|c|c|c|c|c|}
\hline Methods & \multicolumn{5}{|c|}{ Price } & \multicolumn{3}{|c|}{ YTM } & \multicolumn{4}{|c|}{$\begin{array}{l}\text { Stability } \\
\text { (price) }\end{array}$} & \multicolumn{3}{|c|}{$\begin{array}{c}\text { Stability } \\
\text { ( YTM) }\end{array}$} & \multirow{2}{*}{$\begin{array}{c}\text { Sum } \\
30 \\
\end{array}$} \\
\hline$N S-11$ & 3 & 3 & 3 & 1 & 1 & 1 & 1 & 1 & 4 & 4 & 4 & 1 & 1 & 1 & 1 & \\
\hline$N S-1$ & 3 & 3 & 3 & 5 & 1 & 1 & 1 & 1 & 4 & 4 & 4 & 5 & 1 & 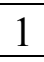 & 1 & 38 \\
\hline NS-10 & 1 & 1 & 1 & 4 & 4 & 4 & 5 & 5 & 1 & 1 & 1 & 4 & 5 & 5 & 5 & 47 \\
\hline$N S-13$ & 5 & 5 & 5 & 3 & 3 & 3 & 3 & 3 & 3 & 3 & 3 & 3 & 3 & 3 & 3 & 51 \\
\hline NS-0 & 1 & 1 & 1 & 6 & 4 & 4 & 5 & 5 & 1 & 1 & 1 & 6 & 5 & 5 & 5 & 51 \\
\hline NS-12 & 6 & 6 & 6 & 2 & 6 & 6 & 4 & 4 & 6 & 6 & 6 & 2 & 4 & 4 & 4 & 72 \\
\hline
\end{tabular}

\begin{tabular}{|l|c|c|c|c|c|c|c|c|}
\hline & \multicolumn{3}{|l|}{ Length } & \multicolumn{3}{|c|}{ Smoothness } & Sum & Sum1 \\
\hline $\boldsymbol{N S - 1}$ & 1 & 4 & 2 & 1 & 1 & 1 & 10 & 48 \\
\hline $\boldsymbol{N S - 1 1}$ & 1 & 4 & 2 & 1 & 1 & 4 & 13 & 43 \\
\hline $\boldsymbol{N S - 1 3}$ & 6 & 1 & 1 & 3 & 3 & 3 & 17 & 68 \\
\hline $\boldsymbol{N S - 0}$ & 3 & 2 & 4 & 4 & 6 & 6 & 25 & 76 \\
\hline $\boldsymbol{N S - 1 0}$ & 3 & 2 & 4 & 4 & 6 & 6 & 25 & 77 \\
\hline $\boldsymbol{N S - 1 2}$ & 5 & 6 & 6 & 6 & 4 & 1 & 28 & 100 \\
\hline
\end{tabular}

Ranking of the methods according to separate criteria is summarized in Tab. 9. The column denoted as Sum is a sum of rankings in a row of the table. The column denoted as Suml shows a sum of rankings according to all the criteria. The best stability in prices exhibits method $N S-10$ while in YTM's it is method NS-11. Methods NS-11 and NS-10 show the best performance if the criteria of the least error of the observed and theoretical prices are considered. The least error in terms of YTM (Yield To Maturity) reaches method NS-10. The minimum length and smoothness of the computed yield curves was obtained for method NS-1. The overall winner is method NS- 11 .

\section{Conclusion}

Results presented in this paper were based on interest rate estimates from the Czech coupon bond market, which is characterized by a relatively low number of bonds, by moderate liquidity and periodically reduced efficiency. We explored Nelson-Siegel method to create yield curves. This approach produced a reasonably looking spot and forward yield curves. Our attempt to assign weights to each bond reflecting its liquidity 
was not successful. After substantial experimentation, however, we found the approach to be a stable and potentially useful. This must be clarified in our subsequent work when compared to other methods (methods using B-splines, Fourier method, Svensson method).

\section{References:}

[1] Bolder, D. J. - Gusba, S. (2002): Exponentials, Polynomials and Fourier Series: More Yield Curve Modelling at the Bank of Canada. [on-line], Ottawa, Bank of Canada Working Paper, no. 2002-29, c2002, [cited $10^{\text {th }}$ September, 2012], $<$ http://www.bankofcanada.ca/wp-content/uploads/2010/02/wp0229.pdf $>$.

[2] Fisher, M. - Nychka, D. - Zervos D. (1994): Fitting the Term Structure of Interest Rates with Smoothing Splines. U. S. Federal Reserve Board Working Paper, c1994, [cited 10 $0^{\text {th }}$ September, 2012], $<$ http://www.markfisher.net/ mefisher/papers/yc.pdf $>$.

[3] Gauthier, G. - Simonato, J. G. (2012). Linearized Nelson-Siegel and Svensson Models for the Estimation of Spot Interest Rates. European Journal of Operational Research, 2012, vol. 219, no. 2, pp. 442-451.

[4] Gilli, M. - Grosse, S. - Schumann, E., (2010): Calibrating the Nelson-Siegel-Svensson Model. [on-line], Giessen, Computational Optimization Methods in Statistics, Econometrics and Finance Working Papers Series, Working Paper 031, c2010, [cited $10^{\text {th }}$ September, 2012], <http://comisef.eu/files/wps031.pdf >.

[5] Kladívko, K. (2008). Česká výnosová křivka od roku 1999 do současnosti. [on-line], Praha, Ministry of Finance of The Czech republic, c2008, [cited $10^{\text {th }}$ September, 2012], $<$ http://www2.humusoft.cz/www/papers/finsem09/kamil_kladivko.p $\mathrm{df}>$.

[6] Li, B. - DeWetering, E. - Lucas, G. - Brenner, R. - Shapiro. A (2001): Merrill Lynch Exponential Spline Model. New York, Merrill, 2001.

[7] Málek, J. (2005): Dynamika úvěrových měr a úrokové deriváty. Praha, Ekopress, 2005.

[8] Málek, J. - Radová, J. - Šterba, F. (2007): Yield curve construction using government bonds in the Czech Republic. Politická ekonomie, 2007, vol. 55, no. 6, pp. 792-827. 
Hladíková H. - Radová J.: Term Structure Modelling Using Nelson-Siegel Model.

[9] Marciniak, M., (2006): Yield Curve Estimation at the National Bank of Poland. Bank i kredyt, 2006, vol. 37, no.3, pp.52-74.

[10] Nelson, C. R. - Siegel, A. F. (1987): Parsimonious Modeling of Yield Curve. Journal of Business 1987, vol. 60, no. 4, pp.473-489.

[11] Slavík, M. (2001): Interest Time Structure and Domestic Bond Prices. Finance a úvěr, 2001, vol. 51, no.11, pp. 591-606.

[12] Svensson, L. E. (1994): Estimating and Interpreting Forward Interest Rates: Sweden 1992-1994. [on-line], Washington, D. C., National Bureau of Economic Research Working Paper no. 4871, c1994, [cited $10^{\text {th }}$ September, 2012], <http://www.nber.org/papers/w4871.pdf?new_window $=1>$.

[13] BIS (2005): Zero-coupon Yield Curves: Technical Documentation. [on-line], Basel, Bank for International Settlements, c2005, [cited $10^{\text {th }}$ September, 2012],

$<$ http://www.bis.org/publ/bppdf/bispap25.pdf $>$. 


\title{
Term Structure Modelling by Using Nelson-Siegel Model
}

\author{
Hana HLADÍKOVÁ - Jarmila RADOVÁ
}

\begin{abstract}
Zero coupon rates are not observable in the market for a range of maturities. Therefore, an estimation methodology is required to derive the zero coupon yield curves from observable data. If we deal with approximations of empirical data to create yield curves it is necessary to choose suitable mathematical functions. We use parametric model of Nelson and Siegel. The current mathematical apparatus employed for this kind of approximation is outlined. This theoretical background is applied to an estimation of the zero-coupon yield curve derived from the Czech coupon bond market. There are many methodologies and each can provide surprisingly different results. Nevertheless, each seeks to provide an estimation that fit the data well while maintaining an easily interpretable form. On an initial test data sample we have not faced any problems, reported elsewhere, of not having found the global optimum or having found multiple local minima.
\end{abstract}

Key words: Yield curve estimation; Nelson-Siegel model; Nonlinear least squares.

JEL classification: G60, G30; M30. 